\title{
Inflammatory Cell Distribution within and along Asthmatic Airways
}

\author{
KATHLEEN J. HALEY, MARY E. SUNDAY, BARRY R. WIGGS, HARRY P. KOZAKEWICH, JOHN J. REILLY, \\ STEVEN J. MENTZER, DAVID J. SUGARBAKER, CLAIRE M. DOERSCHUK, and JEFFREY M. DRAZEN \\ Pulmonary and Critical Care Division, Departments of Medicine and Departments of Surgery and Pathology, Brigham and Women's \\ Hospital and Harvard Medical School; Departments of Pathology, Children's Hospital and Harvard Medical School, and Physiology \\ Program, Harvard School of Public Health, Boston, Massachusetts; and Pulmonary Research Laboratory, St. Paul's Hospital, \\ University of British Columbia, Vancouver, British Columbia, Canada
}

\begin{abstract}
Asthmatic airways are infiltrated with inflammatory cells that release mediators and cytokines into the microenvironment. In this study, we evaluated the distribution of CD45-positive leukocytes and eosinophils in lung tissue from five patients who died with severe asthma compared with five patients with cystic fibrosis. For morphometric analysis, the airway wall was partitioned into an "inner" area (between basement membrane and smooth muscle) and an "outer" area (between smooth muscle and alveolar attachments). Large airways (with a perimeter greater than $\mathbf{3 . 0} \mathbf{~ m m}$ ) from patients with asthma or cystic fibrosis had a greater density of CD45-positive cells $(p<0.05)$ and eosinophils $(p<0.001)$ in the inner airway region compared with the same airway region in small airways. Furthermore, in small airways, asthmatic lungs showed a greater density of CD45-positive cells ( $p<$ 0.01 ) and eosinophils ( $p<\mathbf{0 . 0 1}$ ) in the outer compared with the inner airway wall region. These observations indicate that there are regional variations in inflammatory cell distribution within the airway wall in patients with asthma that are not observed in airways from patients with cystic fibrosis. We speculate that this inflammatory cell density in peripheral airways in severe asthma may relate to the peripheral airway obstruction characteristic of this condition. Haley KJ, Sunday ME, Wiggs BR, Kozakewich HP, Reilly JJ, Mentzer SJ, Sugarbaker DJ, Doerschuk CM, Drazen JM. Inflammatory cell distribution within and along asthmatic airways. AM J RESPIR CRIT CARE MED 1998;158:565-572.
\end{abstract}

$\mathrm{H}$ istopathologic studies of airways from patients with asthma have established that asthma is a process involving the entire bronchial tree, which includes infiltration of the airway wall with inflammatory cells and thickening of all components of the airway wall (1-11). A mong the critical findings in such studies has been an appreciation of the importance of histopathologic changes in peripheral airways with respect to the observed physiologic changes in asthma (1, 4, 5, 7, 9, 12-14). Investigations examining the peripheral cellular infiltrates in fatal asthma have demonstrated abundant inflammatory cells in the lung periphery $(6,9,13,15)$. A dditional studies have compared the areas of airway wall subdivisions in asthma (1, $12,14)$, and have compared the epithelial inflammation with the remainder of the airway wall (15). However, they do not detail the location of the inflammatory infiltrate within the subepithelial portion of the airway wall, or whether the location of the inflammatory infiltrate within the subepithelial portion of the airway wall differs between the large and small airways. The goal of this study was to address these unan-

(Received in original form May 14, 1997 and in revised form January 14, 1998) Supported by NIG 5U01AI3159904 and SCOR Grant HL56383-02 from the National Institutes of Health.

Correspondence and requests for reprints should be addressed to Jeffrey M. Drazen, M.D., Pulmonary and Critical Care Division, Brigham and Women's Hospital, 75 Francis Street, Boston, MA 02115.

Am J Respir Crit Care Med Vol 158. pp 565-572, 1998

Internet address: www.atsjournals.org swered questions of whether there are differences in the inflammatory infiltrate within the subepithelial regions of the airway wall and whether the patterns of inflammatory cells differ between large and small airways.

Evaluating such differences might be informative for several reasons. If the histopathology of the inflammatory infiltrate differs within the subepithelial component of the airway wall in large and small airways, such differences could potentially result in varying response to stimuli in airways of different sizes. A Iternatively, if the inflammatory infiltrate varies within the airway wall, local gradients of inflammatory mediators could occur that might influence the response of airway wall components to a phlogistic environment. In particular, many of the mediators associated with asthma such as leukotrienes (16), tumor necrosis factor $(17,18)$, neuropeptides (1921), purines (22), prostaglandins (23), and eotaxin (24) are rapidly inactivated, and so would be expected to act only ephemerally in the microenvironment. Therefore, regional differences in inflammatory cell density could have important implications for the pathobiology of asthma.

B ecause the distribution of the inflammatory infiltrate both within the airway wall and between the central and peripheral airways of asthmatics has not been established, we examined the distribution of leukocytes, identified by immunostaining as expressing the pan-leukocyte marker CD 45 antigen (leukocyte common antigen), as well as eosinophils, in central and peripheral airways of patients who died with or as a result of severe asthma. We compared these results with a similar anal- 
ysis of lungs removed from patients with another chronic inflammatory lung disease, cystic fibrosis. We chose cystic fibrosis as an example of severe, chronic airway inflammation having an etiology distinct from asthma. The use of samples from these two syndromes allowed us to compare chronic pulmonary inflammation affecting both the large and the small airways, but which resulted from different pathophysiologic stimuli. 0 ur data indicate that there are distinct distributions of inflammatory cells in lungs of patients with these disease entities.

\section{METHODS}

\section{Tissue Acquisition}

Pathology records from the Children's Hospital and Brigham and Women's Hospital were reviewed to identify all postmortem examinations that listed asthma as the primary or major contributing cause of death. A utopsy tissue from patients whose cause of death as identified by the postmortem examination was status asthmaticus $(n=4)$ or having asthma listed as one of the primary diagnoses contributing to the patient's death $(n=1)$ was identified. I n addition, surgical specimens of cystic fibrosis lung removed at the time of transplant $(n=$ 5) were identified from pathology records as well as five cases in which cystic fibrosis was listed as the primary cause of death. The samples from cystic-fibrosis-related deaths were used to evaluate whether the patterns of inflammatory cells were different in autopsy samples from those in surgical samples. This evaluation was qualitative and served only to confirm that the patterns of inflammatory cells could be expected to remain approximately stable in postmortem specimens. The paraffin tissue blocks were screened using a hematoxylineosin stain to identify the presence of suitable airways for each case. $\mathrm{O} n$ the basis of this review, between one and three blocks were chosen from each case. From these materials, histologic sections, five microns thick, were cut from formalin-fixed paraffin-embedded tissue blocks. A II material was obtained under approval of the $\mathrm{H}$ ospital $\mathrm{E}$ thics $\mathrm{Com}$ mittee.

\section{Cell Identification}

Serial tissue sections were stained with M asson's trichrome for identification of smooth muscle, with hematoxylin-eosin (H and $E$ ) for identification of eosinophils, and by immunostaining using a murine monoclonal anti-CD 45 antibody to identify leukocytes. A modified avidin-biotin complex (A BC) technique (25) was used for CD 45 identification. The sections were dewaxed in xylenes, rehydrated in ethanol, and incubated in a microwave oven on high power for $30 \mathrm{~s}$. Nonspecific immunoglobulin binding was blocked with $10 \%$ normal horse serum. The primary murine antihuman CD 45 monoclonal antibodies (murine IgG ${ }_{1}$, Dako clones 2B 11 and PD 7/26; D ako Corp., Carpinteria, CA ), diluted to $35 \mu \mathrm{g} / \mathrm{ml}$ in phosphate-buffered saline with $2 \%$ bovine serum albumin (PBS/BSA ), were applied to tissue sections and incubated at $4^{\circ} \mathrm{C}$ overnight in a humidified chamber; negative controls, using the murine monoclonal IgG ${ }_{1}$ M O PC-21 (Sigma Chemical Co., St. Louis, M O) diluted to $35 \mu \mathrm{g} / \mathrm{ml}$, were incubated in the same fashion. The sections were incubated with the secondary antibody, a biotinylated horse antimouse IgG (V ector L aboratories, B urlingame, CA ) diluted in PBS/BSA containing $5 \mu \mathrm{l} / \mathrm{ml}$ normal human serum, at $4^{\circ} \mathrm{C}$ for $2 \mathrm{~h}$. Endogenous peroxidase activity was subsequently quenched using methanol containing $1 \%$ hydrogen peroxide. A BC standard (V ector Laboratories) was made according to the manufacturer's instructions, applied to sections, and incubated at room temperature for $1 \mathrm{~h}$. I mmunopositivity was localized using the chromagen diaminobenzidine $(0.025 \% \mathrm{wt} / \mathrm{vol})$ in PBS and $0.1 \%$ hydrogen peroxide. The internal positive control consisted of prominent alveolar macrophage staining. Masson's trichrome stain was carried out according to the manufacturer's instructions (Sigma). To better demonstrate eosinophils, $\mathrm{H}$ and $\mathrm{E}$ staining was performed with the addition of a $0.1 \% \mathrm{wt} / \mathrm{vol}$ azure II (Sigma) wash after the eosin incubation (26).

\section{Morphometrics}

Morphometry was performed using a Nikon microscope equipped with a drawing arm. A t magnification $\times 200$, a cursor was projected onto the microscopic field and the images were outlined onto a digitizing pad interfaced with a computer running morphometry software (SigmaScan; J andel Scientific, San R afael, CA ). The trichrome stain was used to locate smooth muscle boundaries. In each section, all airways demonstrating smooth muscle surrounding at least $50 \%$ of the perimeter and having well-demarcated alveolar attachments were included in morphometric analysis. The airway size was determined by both histologic criteria and basement membrane perimeter (27), which was traced using the digitizing pad. A II large airways (for LCA analysis, $n=17$ asthmatic large airways, $n=8$ cystic fibrosis large airways; for $\mathrm{H}$ and $\mathrm{E}$ analysis, $\mathrm{n}=16$ asthmatic large airways, $\mathrm{n}=11$ large cystic fibrosis airways) had ciliated columnar epithelium, and most contained cartilage or were visible to the unaided eye; these airways had perimeter lengths from 3.0 to $21.9 \mathrm{~mm}$. Three of the five asthmatic cases had large airways suitable for LCA and $H$ and $E$ morphometric analysis, with the number of airways per case ranging from two to nine. Four of the five cystic fibrosis cases had large airways suitable for LCA morphometric analysis, with the number of airways per case ranging from one to three. Three of the five cystic fibrosis cases had large airways suitable for $\mathrm{H}$ and $\mathrm{E}$ morphometric analysis, with the number of airways per case ranging from one to three. Small airways (for LCA analysis, $n=35$ asthmatic small airways, $n=13$ cystic fibrosis airways; for $\mathrm{H}$ and $\mathrm{E}$ analysis $\mathrm{n}=43$ asthmatic small airways, $\mathrm{n}=11$ cystic fibrosis small airways) were defined as muscular membranous bronchioles; in addition, any airway with cuboidal epithelium was defined as "small." The small airways had perimeter lengths from $0.2 \mathrm{~mm}$ to $3.6 \mathrm{~mm}$. A II the asthmatic small airway perimeters were less than or equal to $3.0 \mathrm{~mm}$. O ne of the cystic fibrosis small airways demonstrated cuboidal epithelium, and was classified as "small," even though its perimeter was $3.6 \mathrm{~mm}$; the remaining 10 small cystic fibrosis airways all had perimeters less than $3.0 \mathrm{~mm}$. A II of the asthmatic cases had small airways suitable for LCA and $\mathrm{H}$ and $\mathrm{E}$ morphometric analysis, with the number of airways per case ranging from five to 11 . Four of the five cystic fibrosis cases had small airways suitable for $L C A$ and $H$ and $E$ morphometric analysis, with the number of airways per case ranging from one to seven.

For purposes of cell counting, the airway wall cross section was subdivided into two regions: one was defined as the "inner" area and contained the distal edge of the basal lamina to the luminal edge of the smooth muscle, whereas the "outer" area was defined as the region from the outer edge of the smooth muscle to the alveolar attachments (Figure 1). These areas were outlined by projecting a cursor onto the microscopic field by means of a drawing tube. In areas where the muscle was discontinuous, the approximate site of the muscle boundary was extrapolated by visually connecting two adjacent muscle bundles with a straight line. In cartilaginous airways, the area occupied by cartilage was excluded. Elements of the airway wall such as mucous glands and their associated inflammatory cells were included in area and cell count analyses; cells inside capillaries contained in the airway wall were excluded from analyses. Two to three nonadjacent wedge-shaped segments were counted for each airway, which were approximately evenly spaced around the airway (that is, at 2, 6, and 10 o'clock); to be eligible for morphometric analysis, a segment had to have both "inner" and "outer" areas. A fter the segments and areas were delineated, the inflammatory cells (CD 45-positive cells or eosinophils) were counted. Cell densities were calculated, and expressed as the number of cells per square millimeter tissue. The use of cell density per square millimeter tissue allowed the inflammatory infiltrate to be compared among airways cut along different angles.

\section{Statistics}

The data analysis for this study required a method of comparing multiple factors ("inner" density, "outer" density, and the difference between "inner" and "outer" densities) in different sized airways (large and small) in two diagnoses (cystic fibrosis and asthma). We found that a two-way ANOVA, nested for diagnosis, provided the best model for this analysis. A further advantage of this technique was that it allowed comparison of different numbers of airways between diagnostic groups. Grouped results were expressed as means \pm standard error of the mean (SE M). D ifferences were accepted as statistically significant at $p<0.05(28)$. 


\section{RESULTS}

\section{Clinical Characteristics and Pathologic Features}

The clinical characteristics of the patients studied are provided in Table 1; the average age for both groups was similar: $28.2 \mathrm{yr}$ (range, 5 to $56 \mathrm{yr}$ ) for the asthmatics and $28.0 \mathrm{yr}$ (range, 23 to $31 \mathrm{yr}$ ) for the patients with cystic fibrosis. T wo of the patients with asthma and one of the patients with cystic fibrosis were receiving steroids chronically (oral or inhaled), two asthmatic patients and four patients with cystic fibrosis did not receive steroids regularly (there was no available information about steroid use for one of the asthmatic patients). A II asthmatic patients received steroids during their hospital course. The duration of the final illness in the asthmatics ranged from less than $24 \mathrm{~h}$ to $25 \mathrm{~d}$. R ecord review indicated that none of the patients in either group used tobacco products.

R eview of the $\mathrm{H}$ and $\mathrm{E}$ staining confirmed histology consistent with the previously assigned diagnoses in all cases. The asthmatic inflammatory infiltrates demonstrated a mixed celIularity composed of lymphocytes, eosinophils, macrophages, and neutrophils. The cystic fibrosis infiltrates consisted predominantly of neutrophils with scattered eosinophils noted in the cartilaginous airways. The pattern of inflammatory cell infiltration did not differ qualitatively between the samples of cystic fibrosis lung obtained from autopsy and the surgical specimens of cystic fibrosis lung.

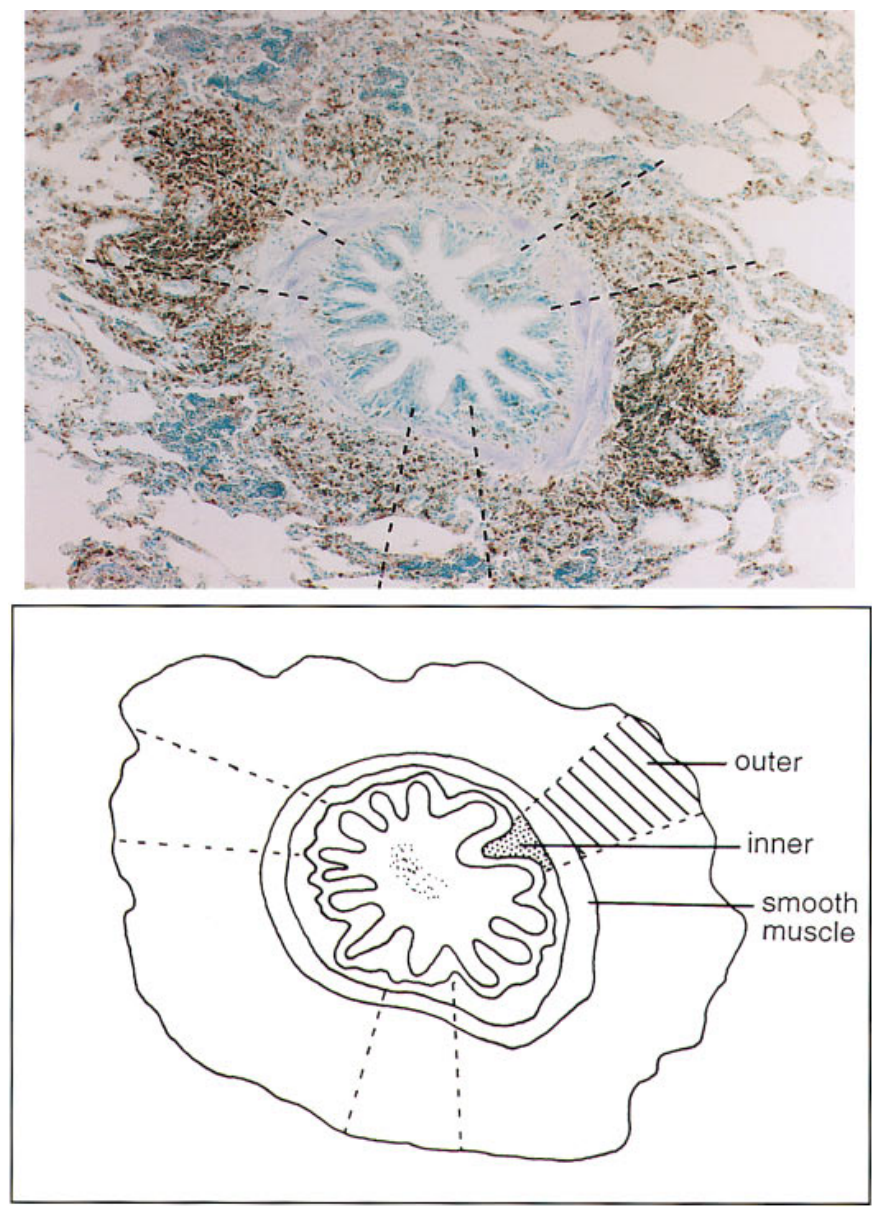

Figure 1. Schematic drawing of "inner" and "outer" airway wall regions. The "inner" region of the airway is defined as the area between the basement membrane and the smooth muscle, and the "outer" region of the airway is defined as the area between the smooth muscle and the alveolar attachments.

\section{CD45-positive Cells}

A Il the samples from asthmatic subjects demonstrated a prominent inflammatory cell infiltrate surrounding cartilaginous and membranous airways; however, there were substantial differences in the location of these infiltrates within the large and small airways and within the airway wall (Figure 2 and Table 2). Compared with the small airways (Figure $2 B$ ), the large airways (Figure $2 A$ ) had a significantly greater $(p<$ 0.05 ) density of CD 45-positive cells in the "inner" airway wall (Table 2). H owever, the density of CD 45-positive cells located in the "outer" airway wall region was not statistically different between the large and small airways (Table 2). Within large airways, the CD45-positive cells were located in both the "inner" and the "outer" airway regions (Table 2). The small airways from asthmatic subjects contained a significantly greater ( $p<0.01$ ) density of CD 45-positive cells in the "outer" versus the "inner" region (Figure $2 \mathrm{~B}$ and Table 2 ). Furthermore, comparison of the differences between the "inner" and "outer" regions in the large versus the small airways demonstrated a significant $(p<0.05)$ difference in the location of the inflammatory infiltrate in the large and small airways (Figure $3 A$ ), with a predominantly "outer" infiltrate in the small airways. No differences in patterns were observed in airways obtained from subjects with and without a history of chronic steroid use (data not shown).

Lungs from subjects with cystic fibrosis demonstrated CD 45-positive cells infiltrating both the large and the small airways, with CD 45-positive cells found in both the "inner" and the "outer" regions in large and small airways (Figures $2 \mathrm{C}$ and 2D ). Compared with the small airways, the large airways had a significantly greater density of CD 45-positive cells in the "inner" airway region ( $p<0.05$ ) (Table 2 ). In contrast to the asthmatic samples, there were no significant differences between the densities of the CD 45-positive cells in the "inner" and "outer" airway wall regions in either the large or the small airways (Figure $3 \mathrm{~A}$ ). In order to facilitate comparisons, the "inner" airway wall inflammatory cell density in airways from cystic fibrosis lungs were matched to asthmatic airways. In these samples, the differences in CD 45-positive cell distribution between the cystic fibrosis and asthmatic airways persisted. That is, in these airways matched for "inner" airway wall region cell densities, the cystic fibrosis small airways did not demonstrate significant differences in the density of CD 45positive cells between the "inner" and "outer" regions. However, the asthmatic small airways demonstrated an "outer" region distribution of CD 45-positive cells (data not shown).

\section{Eosinophils}

The density of the eosinophilic infiltrates also varied with both airway size and location within the airway wall (Table 3). $W$ ithin the "inner" region of the airway wall, there was a sig-

TABLE 1

\section{CLINICAL CHARACTERISTICS OF SUBJECTS WITH} ASTHMA AND CYSTIC FIBROSIS

\begin{tabular}{lrrcc}
\hline Diagnosis & Age & Sex & Duration of Acute Symptoms & Chronic Steroids \\
\hline Asthma & 56 & $\mathrm{~F}$ & $26 \mathrm{~d}$ & No \\
Asthma (status) & 49 & $\mathrm{M}$ & $<24 \mathrm{~h}$ & No \\
Asthma (status) & 17 & $\mathrm{~F}$ & $<24 \mathrm{~h}$ & Yes \\
Asthma (status) & 14 & $\mathrm{M}$ & $2 \mathrm{~d}$ & Yes \\
Asthma (status) & 5 & $\mathrm{~F}$ & Not applicable & Unknown \\
Cystic fibrosis & 30 & $\mathrm{M}$ & Not applicable & No \\
Cystic fibrosis & 31 & $\mathrm{M}$ & Not applicable & No \\
Cystic fibrosis & 31 & $\mathrm{~F}$ & Not applicable & Yes \\
Cystic fibrosis & 23 & $\mathrm{~F}$ & Not applicable & No \\
Cystic fibrosis & 25 & $\mathrm{~F}$ & & No \\
\hline
\end{tabular}



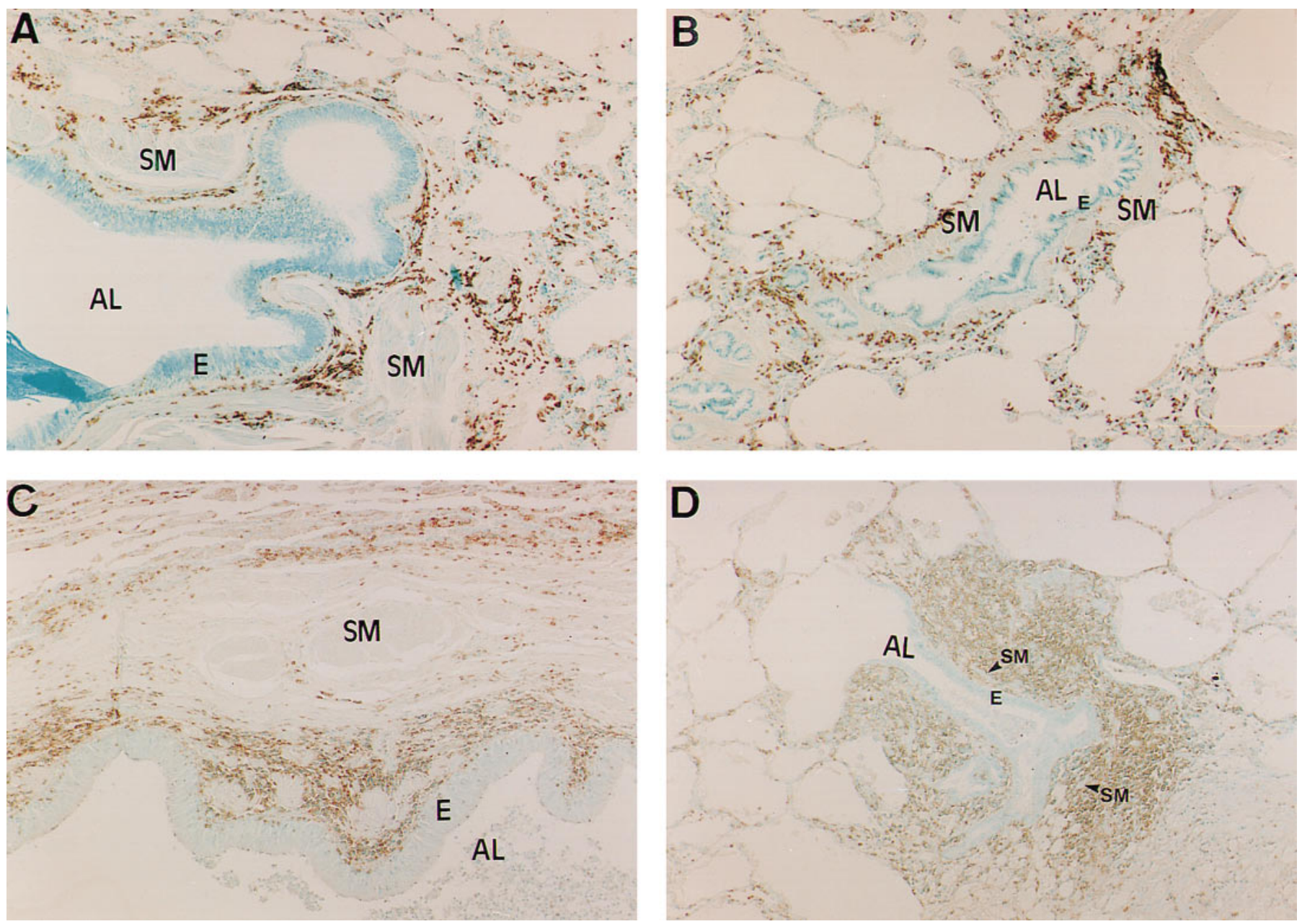

Figure 2. Immunostaining for CD45. (A) Large asthmatic airway. (B) Small asthmatic airway, demonstrating "outer" pattern of inflammatory cell distribution. (C) Large cystic fibrosis airway. (D) Small cystic fibrosis airway demonstrating uniformly distributed CD45-positive cells. Original magnification $\times 250$. AL = airway lumen; $E=$ epithelium; $S M=$ smooth muscle.

nificantly greater density of eosinophils in the large versus the small asthmatic airways ( $p<0.001$ ). In contrast, the "outer" airway wall region did not demonstrate significant differences in eosinophil density between the large and the small airways (Table 3). Within the large asthmatic airways a significantly greater density of eosinophils was found in the "inner" region compared with the "outer" region $(p<0.01)$. In contrast, in small asthmatic airways there was an "outer" eosinophil distribution (i.e., significantly more cells per area in the "outer" than in the "inner" regions) ( $p<0.01$ ). The difference in cell density between the "inner" and "outer" regions in the large versus the small airways was significant ( $p<0.001$ ) (Figure 3B ).

In airways from patients with cystic fibrosis, there were only scattered eosinophils that were predominantly associated with large rather than small airways (Table 3 ). The distribution of this cell type did not vary significantly within the airway wall in either the large or the small airways. There were nonsignificant trends for the densities of eosinophils to be greater in large asthmatic "inner" airways $(p=0.069)$ and small asthmatic "outer" airways $(p=0.081)$ compared with the same regions in the airways from patients with cystic fibrosis.

\section{DISCUSSION}

O ur data demonstrate that the distribution of CD 45-positive cells and eosinophils within the airway wall varies significantly between large and small asthmatic airways. The small asthmatic airways had a preponderance of their inflammatory cells, including eosinophils in particular, in the "outer" region, whereas the greatest density of eosinophils in the large asthmatic airways was in the "inner" region. A irways from patients with cystic fibrosis demonstrated a different pattern of inflammatory cells. The density of the CD 45-positive cells in the small cystic fibrosis airways did not vary between the "inner" and the "outer" regions.

TABLE 2

VARIATION IN CD45-POSITIVE CELLS WITH AIRWAY WALL REGION AND AIRWAY SIZE

\begin{tabular}{ccr}
\hline Diagnosis/Airway Size & $\begin{array}{c}\text { Inner Density } \\
\text { (cells/mm }\end{array}$ & $\begin{array}{c}\text { Outer Density } \\
\left.\text { (cells/ } \mathrm{mm}^{2} \pm \text { SEM }\right)\end{array}$ \\
\hline Asthma, $\mathrm{n}=5$ & & \\
Large, $\mathrm{n}=17$ & $14,220 \pm 1,760^{*}$ & $8,050 \pm 1,860$ \\
Small, $\mathrm{n}=43$ & $8,520 \pm 740$ & $22,040 \pm 4,310^{\dagger}$ \\
Cystic fibrosis, $\mathrm{n}=5$ & $20,710 \pm 5,860^{*}$ & $8,330 \pm 1,390$ \\
Large, $\mathrm{n}=8$ & $16,120 \pm 4,110$ & $11,330 \pm 2,570$ \\
Small, $\mathrm{n}=11$ &
\end{tabular}

* Designates large airway "inner" airway wall density greater than small airway "inner" airway wall density, $\mathrm{p}<0.05$.

† Designates small airway "outer" density greater than small airway "inner" density, $\mathrm{p}<0.01$. 

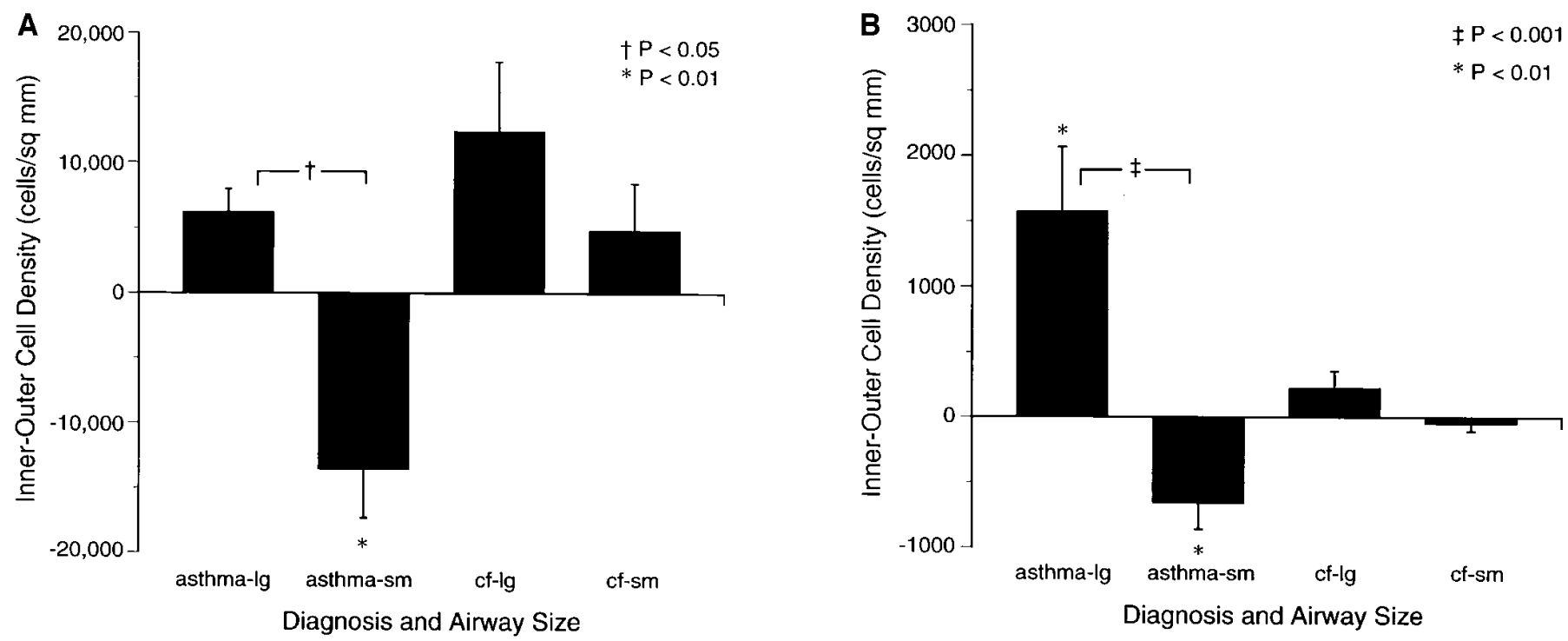

Figure 3. Differences between the "inner" and "outer" inflammatory cell densities, where regions with equivalent cell densities would yield a difference of zero; positive values indicate greater "inner" region density, and negative values indicate greater "outer" region density. (A) CD45-positive inflammatory cells. (B) Eosinophils. *Designates a statistically significant difference at $p<0.01$ compared with zero. ${ }^{\dagger}$ Designates a statistically significant difference at $p<0.05$ comparing large and small airways. ${ }^{\ddagger}$ Designates a statistically significant difference at $\mathrm{p}<0.001$ comparing large and small airways. Bars indicate one standard error of the mean. Abbreviations: cf $=$ cystic fibrosis; lg $=$ large airway; $\mathrm{sm}=$ small airway.

O ne of the most important aspects of this study was the use of surgical and autopsy specimens, which allowed us to sample both the large and small airways and to examine the inflammatory infiltrate throughout the entire airway circumference instead of limiting analyses to the subepithelial area obtained by endobronchial biopsy. A Ithough the data from endobronchial biopsy and bronchoalveolar lavage studies have yielded insights into the immunologic mechanisms of asthma, these sampling techniques are limited. Neither technique samples the entire airway wall, and only cartilaginous bronchi are accessible to endobronchial biopsies. O ur data indicate that leukocyte types and densities in the central subepithelial regions cannot be extrapolated either to deeper areas of the airway wall or to the peripheral bronchioles, and that endobronchial biopsies of more peripheral airways may not sample an "outer" infiltrate.

However, the use of archival autopsy and surgical specimens also imposed several limitations on this study. In particular, we were not able to control the tissue fixation in the samples, and frequently had only a limited number of airways to evaluate from each case. The differences in cell fixation may have led to case-to-case variation in immunostaining sensitivity; however, comparing the staining to an internal positive control (alveolar macrophage staining) minimized this problem. Q ualitative comparison of the surgical and autopsy specimens from cystic fibrosis lung did not demonstrate any differences in inflammatory cell patterns. Therefore, it is likely that the differences observed in this study were due to the disease processes rather than to the use of surgical and autopsy tissue. We maximized the number of airways suitable for morphometric analysis by evaluating cell densities per square millimeter of tissue.

The results of this study support and extend previous investigations examining the differences between large and small airways as well as the prominent small airway changes in fatal asthma. Several investigative groups have shown that the thickening of the airway wall components can be demonstrated in airways of all sizes $(1,3,7,9,11,13)$. Carroll and colleagues (1), comparing lungs from patients with fatal and nonfatal asthma with lungs from normal control subjects, demonstrated that the relative changes in the airway wall components varied with the size of the airway examined. In this study, the cartilaginous airways from nonfatal asthmatic samples were similar to control lung tissue in total airway wall thickness and area of smooth muscle. H owever, the area including the outer border of the smooth muscle and the epithelium, designated as the inner area, was larger in the nonfatal asthmatic lung tissue samples than in the control samples in airways with basement membrane perimeters less than $10 \mathrm{~mm}$. In addition, the airways with basement membrane perimeters between 10 and 18 $\mathrm{mm}$ demonstrated increased inner wall thickness in the tissue from patients with fatal versus those with nonfatal asthma. J ames and colleagues (13), using observed changes in airway wall thickness, demonstrated that the same degree of smooth muscle shortening resulted in approximately tenfold greater increases in airway resistance in small membranous airways

TABLE 3

VARIATION IN EOSINOPHIL DENSITY WITH AIRWAY WALL REGION AND AIRWAY SIZE

\begin{tabular}{|c|c|c|}
\hline Diagnosis/Airway Size & $\begin{array}{c}\text { Inner Density } \\
\text { (cells/mm² } \pm \text { SEM) }\end{array}$ & $\begin{array}{c}\text { Outer Density } \\
\left.\text { (cells } / \mathrm{mm}^{2} \pm \mathrm{SEM}\right)\end{array}$ \\
\hline \multicolumn{3}{|l|}{ Asthma, $n=5$} \\
\hline Large, $\mathrm{n}=16$ & $2,100 \pm 580^{* \dagger}$ & $530 \pm 120$ \\
\hline Small, $\mathrm{n}=35$ & $510 \pm 130$ & $1,160 \pm 250^{\ddagger}$ \\
\hline \multicolumn{3}{|l|}{ Cystic fibrosis, $n=5$} \\
\hline Large, $\mathrm{n}=7$ & $340 \pm 140$ & $120 \pm 70$ \\
\hline Small, $\mathrm{n}=11$ & $60 \pm 60$ & $110 \pm 40$ \\
\hline
\end{tabular}

* Designates large airway "inner" airway wall density greater than small airway "inner" airway wall density, $\mathrm{p}<0.001$.

† Designates large airway "inner" wall eosinophil density significantly greater than large airway "outer" wall eosinophil density, $p<0.01$.

‡ Designates small airway "outer" eosinophil density significantly greater than small airway "inner" eosinophil density, $\mathrm{p}<0.01$. 
compared with cartilaginous airways. These anatomic changes may be related to physiologic changes. L ambert and colleagues (29) used a computer model to differentiate the relative contributions of increases in the submucosal, smooth muscle, and adventitial airway subdivisions with regard to airway constriction. These investigators identified different mechanisms for airway narrowing depending on the airway wall region. Changes in the submucosa led to increased lumenal occlusion for any amount of muscle shortening, whereas increases in the adventitia promoted airway constriction by decreasing the tethering effects of the parenchyma (29).

The components of the peripheral inflammation in fatal asthma have been detailed by many investigators $(2,5,6,8,9$, $15,30,31)$. These studies have shown that the peripheral airways in fatal asthma have an abundant inflammatory infiltrate $(2,5,6,9,15,30,31)$. In addition, several investigators have reported that the pathology found in the membranous bronchioles frequently differs from that in the large airways ( 2 , $5)$, with the small bronchioles frequently demonstrating airway distention instead of constriction. A recent investigation by Synek and colleagues (15), examining specimens obtained from patients with nonfatal and fatal asthma, compared the infiltrates identified in airway epithelium with those in the airway wall as a whole. This study found that, compared with those in mild asthma, the infiltrates associated with fatal asthma demonstrated fewer intraepithelial T-lymphocytes and more eosinophils throughout the airway wall in the larger airways, but no differences were observed between the two types of asthma in the small membranous bronchioles (15). In contrast, a recent study by Carroll and colleagues (31), which examined tissue from patients with fatal asthma, nonfatal asthma, and control patients, demonstrated an increased number of eosinophils in the airway walls from fatal asthma in all airway sizes. This study did not subdivide the peripheral airway wall, and found similar overall densities in the peripheral airways compared with the area in the larger airways between the basement membrane and the outer border of the smooth muscle (31).

The current study did not quantitate epithelial inflammation because of frequent disruption of the epithelial surface in our samples. Instead, our study focused on the location of inflammatory infiltrates within the subepithelial regions of the airway wall and demonstrated that the density of the inflammatory infiltrates was a function of both the location within the airway wall and airway size. Therefore, it is important to consider the various compartments within the airway wall since such an analysis may reveal variations in cell density within the airway wall in a given size airway that might not otherwise be apparent.

The cell densities in the current study are higher than those reported by Synek and colleagues (15). However, a broad range of cell densities in fatal asthma have been documented in the literature (15, 30-34). These variations in cell densities have been found in studies that used either cells per millimeter basement membrane (31-34) or cells per square millimeter tissue $(15,30)$ as a basis of quantitation of the inflammatory infiltrate. We measured the inflammatory infiltrate using cells per square millimeter tissue. We report cell densities that are in the ranges previously reported by Poston and colleagues (35) in asthmatic airways and Faul and colleagues (30) in fatal asthma. Importantly, others have not examined the distribution of this infiltrate within the compartments of the airway wall in asthmatics.

The investigation of A zzawi and colleagues (34) also compared airways from asthmatic patients to airways from patients with cystic fibrosis. These investigators examined total inflammatory cells, eosinophils, and lymphocytes in a zone $115 \mu \mathrm{m}$ deep to the basement membrane in airways with a diameter between 0.5 and $1.5 \mathrm{~cm}$, and they documented an abundant inflammatory infiltrate with both lymphocytes and eosinophils in samples from both the patients with cystic fibrosis and the asthmatics (34). O ur data agree with the findings of the previous investigation regarding the large airway inflammatory cells. In addition, by extending the examination to the smaller airways, our study suggests that the two inflammatory processes may demonstrate a different pattern of cellular recruitment in the periphery: the "outer" pattern of infiltrate found in the asthmatic small airways was not observed in the cystic fibrosis small airways.

The variation in inflammatory cell density seen in the airways of patients with asthma, but not in those of patients with cystic fibrosis, suggests that this "inner" versus "outer" pattern is not part of a generalized, nonspecific pulmonary inflammatory response but may rather be related to the biology of these disorders. The difference between the localization of inflammatory cells in asthmatic and cystic fibrosis airways persisted when subjects were matched for "inner wall" densities. That is, even in airways matched for the "inner wall" densities, the asthmatic small airways demonstrated an "outer" pattern of inflammatory cells that was not observed in cystic fibrosis small airways. This suggests that the localization patterns were due to other factors besides the cell density of the peribronchiolar infiltrate.

Thus, the patterns of the observed inflammatory cell infiltration must result from differences in cell recruitment, retention, or microenvironmental viability. Several factors could have a role in producing these differences. First, the large and small airways differ in their blood supply. The inner regions of the large airways are supplied by the bronchial circulation, whereas the outer airway wall and the small airways are supplied by the pulmonary circulation (36). It is possible that these vessels may have distinctive expression of endothelial adhesion molecules that, in turn, could promote different patterns of inflammatory cell distribution. Second, the cytokine profile produced by local cells within the airway wall and lumen might vary within regions of the airway or size of airway, resulting in the observed differences in patterns of inflammatory cell density. In addition to the large number of cytokines and chemokines known to be produced by the resident inflammatory cells, pulmonary epithelial cells have been documented to produce chemoattractants such as interleukins 6 and 8, eotaxin, R A NTE S, and the eicosanoids (24, 37-40). B ecause the capacity to produce these molecules is modulated by cytokines in the microenvironment, it seems reasonable to speculate that there could be spatial differences within and among the various airways in patients with asthma with respect to the formation of these cytokines. Third, another possible mechanism of differential recruitment relates to the variation in the innervation of the proximal and distal airways (19). This could result in regional differences in responses to those stimuli having effects through inflammatory mediators, including cytokines and chemokines, as well as through activation of nonadrenergic-noncholinergic nerves, leading to the release of neuro-peptides such as tachykinins.

The difference in the pattern of inflammatory cell infiltrates in the lungs affected by asthma compared with cystic fibrosis could be due to differences in the initiating stimulus or to variations in the resulting chemoattractant responses. For example, in advanced cystic fibrosis, the major stimulus to airway inflammation is bacterial infection, provoking a neutrophil-predominant infiltrate, whereas in asthma, a number of etiologic stimuli have been proposed that evoke the inflamma- 
tory response unique to that condition $(41,42)$. The different spatial organization of inflammatory patterns suggests that there is regional organization of pulmonary inflammation, and that this organization is disease-specific.

The functional consequences of the observed variation in inflammatory cell pattern remain speculative. The variations could influence the physiologic effects caused by local production of proinflammatory mediators by inflammatory cells and eosinophils. For example, factors elaborated immediately next to smooth muscle are likely to exert a greater effect than products that must diffuse through the connective tissue of the airway wall. Furthermore, the microenvironment of the airway wall could modify the response of functional elements such as smooth muscle or mucous glands to growth factors or cytokines. Understanding the mechanism of differential distribution of inflammatory cells and evaluating their functional significance remain important unexplored areas to investigate in the pathogenesis of asthma.

\section{References}

1. Carroll, N., J. Elliot, A. M orton, and A. James. 1993. The structure of large and small airways in nonfatal and fatal asthma. A m. Rev. Respir. D is. 147:405-410.

2. Dunnill, M. S. 1960. The pathology of asthma, with special reference to changes in the bronchial mucosa. J. Clin. Pathol. 13:27-33.

3. D unnill, M. S., G. R. M assarella, and J. A . A nderson. 1969. A comparison of the quantitative anatomy of the bronchi in normal subjects, in status asthmaticus, in chronic bronchitis, and in emphysema. Thorax 24:176-179.

4. E bina, M., T. Takahashi, T. Chiba, and M . M otomiya. 1993. Cellular hypertrophy and hyperplasia of airway smooth muscles underlying bronchial asthma: a 3-D morphometric study. A m. Rev. Respir. D is. 148: $720-726$.

5. Houston, J. C., S. de Navasquez, and J. R. Trounce. 1953. A clinical and pathological study of fatal cases of status asthmaticus. Thorax 8:207-213.

6. Huber, H. L., and K. K. Koessler. 1922. The pathology of bronchial asthma. A rch. Intern. M ed. 30:689-760.

7. Kuwano, K., C. H. Bosken, P. D. Paré, T. R. B ai, B. R. Wiggs, and J . C. Hogg. 1993. Small airway dimensions in asthma and in chronic obstructive pulmonary disease. A m. Rev. Respir. D is. 148:1220-1225.

8. M esser, J. W., G. A . Peters, and W. A. B ennett. 1960. Causes of death and pathologic findings in 304 cases of bronchial asthma. D is. Chest 38:616-624.

9. Saetta, M., A . D i Stefano, C. R osina, G. Thiene, and L. M . Fabbri. 1991. Q uantitative structural analysis of peripheral airways and arteries in sudden fatal asthma. A m. Rev. Respir. D is. 143:138-143.

10. Sobonya, R. E . 1984. Q uantitative structural alterations in long-standing allergic asthma. A m. Rev. Respir. D is. 130:289-292.

11. W alzer, I., and T. T. Frost. 1952. D eath occurring in bronchial asthma: a report of five cases. J . Allergy 23:204-214.

12. B oulet, L. P., M. B élanger, and G. Carrier. 1995. A irway responsiveness and bronchial-wall thickness in asthma with or without fixed airflow obstruction. A m. J. Respir. Crit. Care M ed. 152:865-871.

13. James, A. L., P. D. Paré, and J. C. Hogg. 1989. The mechanics of airway narrowing in asthma. A m. Rev. Respir. D is. 139:242-246.

14. Liu, M. C., W. C. Hubbard, D. Proud, B. A. Stealey, S. J. Galli, A. K agey-Sobotka, E. R. B leecker, and L. M. Lichtenstein. 1991. Immediate and late inflammatory responses to ragweed antigen challenge of the peripheral airways in allergic asthmatics: cellular, mediator, and permeability changes. A m. Rev. Respir. D is. 144:51-58.

15. Synek, M., R. Beasley, A. J. Frew, D. Goulding, L. Holloway, F. C. L ampe, W. R. R oche, and S. T. Holgate. 1996. Cellular infiltration of the airways in asthma of varying severity. A m. J. Respir. Crit. Care Med. 154:224-230.

16. Dahlén, S. E., P. Hedqvist, S. H ammarström, and B. Samuelsson. 1980. Leukotrienes are potent constrictors of human bronchi. Nature 288: 484-486.

17. A ckerman, V., M. M arini, E . V ittori, A . B ellini, G. V assali, and S. M attoli. 1994. D etection of cytokines and their cell sources in bronchial biopsy specimens from asthmatic patients: relationship to atopic status, symptoms, and level of airway hyperresponsiveness. Chest 105:687-696.

18. Broide, D. H., M. Lotz, A. J. Cuomo, D. A . Coburn, E. C. Federman, and S. I. W asserman. 1992. Cytokines in symptomatic asthma airways.
J. Allergy Clin. Immunol. 89:958-967.

19. Barnes, P. J . 1986. Neural control of human airways in health and disease. A m. Rev. Respir. Dis. 134:1289-1314.

20. Ollerenshaw, S., D. Jarvis, A . W oolcock, C. Sullivan, and T. Scheibner. 1989. A bsence of immunoreactive vasoactive intestinal polypeptide in tissue from the lungs of patients with asthma. N. Engl. J. M ed. 320: 1244-1248.

21. Ollerenshaw, S. L., D. Jarvis, C. E. Sullivan, and A. J. W oolcock. 1991. Substance $P$ immunoreactive nerves in airways from asthmatics and nonasthmatics. E ur. Respir. J. 4:673-682.

22. Leff, A. R. 1988. Endogenous regulation of bronchomotor tone. A m. Rev. Respir. D is. 137:1198-1216.

23. Liu, M. C., E. R. B leecker, L. M . Lichtenstein, A. Kagey-Sobotka, Y. Niv, T. L. M CL emore, S. Permutt, D. Proud, and W. C. Hubbard. 1990. E vidence for elevated levels of histamine, prostaglandin $D_{2}$, and other bronchoconstricting prostaglandins in the airways of subjects with mild asthma. A m. Rev. Respir. D is. 142:126-132.

24. Ponath, P. D., S. Q in, D. J. R ingler, I. Clark-L ewis, J. W ang, N. K assam, H. Smith, X. Shi, J. A. G onzalo, W. N ewman, J. C. G utierrez-R amos, and C. R. M ackay. 1996. Cloning of the human eosinophil chemoattractant, eotaxin. Expression, receptor binding, and functional properties suggest a mechanism for the selective recruitment of eosinophils. J. Clin. Invest. 97:604-612.

25. H su, S. M ., L. R aine, and H . Fanger. 1981. U se of avidin-biotin-peroxidase complex ( $A B C$ ) in immunoperoxidase techniques: a comparison between $A B C$ and unlabeled antibody (PAP) procedures. J. Histochem. Cytochem. 29:577-580.

26. B eckstead, J. H., P. S. Halverson, C. A. Ries, and D. F. B ainton. 1981. Enzyme histochemistry and immunohistochemistry on biopsy specimens of pathologic human bone marrow. B lood 57:1088-1098.

27. James, A . L., J . C. H ogg, L. A . D unn, and P. D. Paré. 1988. The use of the internal perimeter to compare airway size and to calculate smooth muscle shortening. A m. Rev. Respir. D is. 138:136-139.

28. Mikkiken, G., and D. J ohnson. 1992. A nalysis of nested designs. In A nalysis of M essy $D$ ata: $D$ esigned Experiments. $V$ an N ostrand R einhold, N ew Y ork. 413-423.

29. Lambert, R. K., B. R. Wiggs, K. Kuwano, J. C. Hogg, and P. D. Paré. 1993. Functional significance of increased airway smooth muscle in asthma and CO PD. J. A ppl. Physiol. 74:2771-2781.

30. Faul, J. L., V. J. Tormey, C. Leonard, C. M. Burke, J. Farmer, S. J. Horne, and L. W. Poulter. 1997. Lung immunopathology in cases of sudden asthma death. E ur. Respir. J. 10:301-307.

31. Carroll, N., C. Cooke, and A . James. 1997. The distribution of eosinophils and lymphocytes in the large and small airways of asthmatics. E ur. Respir. J. 10:292-300.

32. Carroll, N., S. Carello, C. Cooke, and A . J ames. 1996. A irway structure and inflammatory cells in fatal attacks of asthma. Eur. Respir. J. 9: 709-715.

33. Sur, S., T. B. Crotty, G. M. Kephart, B. A. Hyma, T. V. Colby, C. E. R eed, L. W. H unt, and G. J. G leich. 1993. Sudden-onset fatal asthma: a distinct entity with few eosinophils and relatively more neutrophils in the airway submucosa? A m. Rev. Respir. D is. 148:713-719.

34. A zzawi, M., P. W. J ohnston, S. M ajumdar, A . B. K ay, and P. K. J effery. 1992. T lymphocytes and activated eosinophils in airway mucosa in fatal asthma and cystic fibrosis. A m. Rev. Respir. D is. 145:1477-1482.

35. Poston, R. N., P. Chanez, J. Y . L acoste, T. Litchfield, T. H. L ee, and J. B ousquet. 1992. I mmunohistochemical characterization of the cellular infiltration in asthmatic bronchi. A m. Rev. Respir. D is. 145:918-921.

36. D effebach, M. E., N. B. Charan, S. Lakshminarayan, and J . Butler. 1987. The bronchial circulation: small, but a vital attribute of the lung. A m. Rev. Respir. Dis. 135:463-481.

37. A rnold, R., B. H umbert, H. Werchau, H. Gallati, and W. K önig. 1994. Interleukin-8, interleukin-6, and soluble tumour necrosis factor receptor type I release from a human pulmonary epithelial cell line (A 549) exposed to respiratory syncytial virus. I mmunology 82:126-133.

38. Koyama, S., S. I. R ennard, G. D. Leikauf, S. Shoji, S. von E ssen, L. Claassen, and R. A. Robbins. 1991. Endotoxin stimulates bronchial epithelial cells to release chemotactic factors for neutrophilia: a potential mechanism for neutrophil recruitment, cytotoxicity, and inhibition of proliferation in bronchial inflammation. J. Immunol. 147: 4293-4301.

39. Standiford, T. J ., S. L. K unkel, M. A . B asha, S. W. Chensue, J. P. L ynch, 3d, G. B. Toews, J. W estwick, R. M. Strieter, and J. P. L ynch. 1990. Interleukin-8 gene expression by a pulmonary epithelial cell line: a model for cytokine networks in the lung. J. Clin. Invest. 86:1945-1953.

40. Wang, J. H., J. L. D evalia, C. X ia, R. J. Sapsford, and R. J. D avies. 1996. Expression of RANTES by human bronchial epithelial cells in vitro 
and in vivo and the effect of corticosteroids. A m. J. Respir. Cell Mol. Biol. 14:27-35.

41. Y ing, S., S. R. D urham, C. J. Corrigan, Q. H amid, and A. B. K ay. 1997. Phenotype of cells expressing mR NA for TH 2-type (interleukin 4 and interleukin 5) and TH 1-type (interleukin 2 and interferon gamma) cytokines in bronchoalveolar lavage and bronchial biopsies from atopic asthmatic and normal control subjects. A m. J. Respir. Cell M ol. Biol. 12:477-487.
42. H umbert, M., S. Y ing, C. Corrigan, G. M enz, J. B arkans, R. Pfister, Q . M eng, J . van D amme, G . O pdenakker, S. R. D urham, and A . B. K ay. 1997. Bronchial mucosal expression of the genes encoding chemokines RANTES and MCP-3 in symptomatic atopic and nonatopic asthmatics: relationship to the eosinophil-active cytokines interleukin (IL )-5, granulocyte macrophage-colony-stimulating factor, and IL-3. A m. J. Respir. Cell Mol. Biol. 16:1-8. 